\title{
Determination of Size and Shape in the 'Moro' Blood Orange and 'Valencia' Sweet Orange Cultivar and its Mutants Using Image Processing
}

\author{
Bahadir SAYINCI ${ }^{1}$, Sezai ERCISLI², Ismail OZTURKㄹ, Zeynep ERYILMAZ , Bunyamin DEMIR \\ ${ }^{1}$ Ataturk University, Faculty of Agriculture, Department of Agricultural Machinery, 25240 Erzurum, Turkey; bsayinci@atauni.edu.tr \\ ${ }^{2}$ Ataturk University, Faculty of Agriculture, Department of Horticulture, 25240 Erzurum, Turkey \\ ${ }^{3}$ West Mediterranean Agricultural Research Institute, 07100 Antalya, Turkey
}

\begin{abstract}
Fruit size and shape are important physical characteristics in designing relevant equipment, sorting, sizing and packaging systems. Therefore, the properties of size and shape of the sweet orange cultivar, 'Valencia', and its three mutants, 'A70', 'A77', and 'A88' were determined by image processing. The blood orange cultivar, 'Moro', was also included in this analysis. The volume of each cultivar and mutant was measured by the liquid displacement method. Linear equations with high $\mathrm{R}^{2}$ values were developed in order to estimate the surface area and geometric mean diameter, which were dependent upon the mass and volume of the orange samples. The results of this study showed that the 'A70' mutant differed from the other mutants and the 'Valencia' cultivar in regard to most physical properties. The 'A70' and 'A88' mutants and the 'Valencia' cultivar had the highest sphericity values, which varied from $96.41 \%$ to $97.18 \%$. The lowest shape factor was found in the 'Valencia' cultivar, with a mean of 0.73 . The elongation of the 'A88' mutant and 'Valencia' (1.07 each) was smaller than that of the other cultivars. The highest coefficient of variance was observed within the 'Valencia' and 'Moro' cultivars in most physical properties, suggesting that the 'Valencia' mutants produce more homogeneous fruits than the 'Valencia' cultivar itself.
\end{abstract}

Keywords: Citrus sinensis, fruit, image processing, projected area, shape factor

\section{Introduction}

Oranges (Citrus sinensis (L.) Osbeck), by far, constitute the most important class of commercial citrus fruits. They are widely cultivated in tropical and subtropical regions for their delicious sweet fruit, which are peeled or cut to avoid the bitter rind and are eaten whole or processed for their fragrant peel or for orange juice extraction.

In 2009, 68.5 million tons of oranges were produced worldwide, primarily in Brazil and in the United States (FAOSTAT, 2009).

A large portion of the world orange crop is used to produce orange juice, as they are pleasant in flavour and colour, and are rich in potassium, vitamin $\mathrm{C}$, and amino acids (Albertini et al., 2006; Niu et al., 2008).

Oranges are grouped into sweet, blood, and bitter oranges (Moufida and Marzouk, 2003). Among them, the sweet oranges are dominant in terms of production amount and are characterized by their unique orange taste.

Turkey, particularly the Mediterranean region, is an important citrus-producing country. Oranges are the third largest fruit crop after grapes and apples, with an annual production of 1.7 million tons in Turkey (FAOSTAT, 2009).

The size and shape of agricultural products are important parameters for determining the proper standards of design of grading, conveying, processing, and packaging systems (Mohsenin, 1986; Tabatabaeefar and Rajabipour,
2005). The image processing method is widely used for determining the properties of size and shape of fruit species. Many researchers have reported on the physical properties (i.e., projected area, equivalent diameter, perimeter, width, thickness, length, sphericity, elongation) of different agricultural products, such as lentil seeds (Lens culinaris) (Fıratlıgil-Durmuş et al., 2008), date fruit (Phoenix dactylifera) (Jahromi et al., 2008), apple (Malus domestica) (Meisami-asl et al., 2009), tangerine (Citrus tangerina) (Khojastehnazhand et al., 2010), citrus fruits (Omid et al., 2010), banana (Musa spp.) (Soltani et al., 2011), tomato (Solanum lycopersicum) (Taheri-Garavand et al., 2011) and walnut (Juglans regia) (Ercisli et al., 2011, 2012).

The objective of this study was to compare the size and shape (i.e., length, minor and major diameters, projected area, geometric mean diameter, sphericity, equivalent diameter, perimeter, shape factor, elongation) of the sweet orange cultivar, 'Valencia', and its three mutants, 'A70', 'A77', and 'A88'. The blood orange cultivar, 'Moro', was also included in the image processing.

\section{Materials and methods}

The cultivars, 'Moro' and 'Valencia', and the three mutants of the 'Valencia' cultivar, 'A70', 'A77', and 'A88', are grown in the West Mediterranean region of Turkey, and were used in this study. Samples were obtained from the province of Antalya, Turkey (located at 36 $56^{\prime} 11^{\prime \prime}$ North 


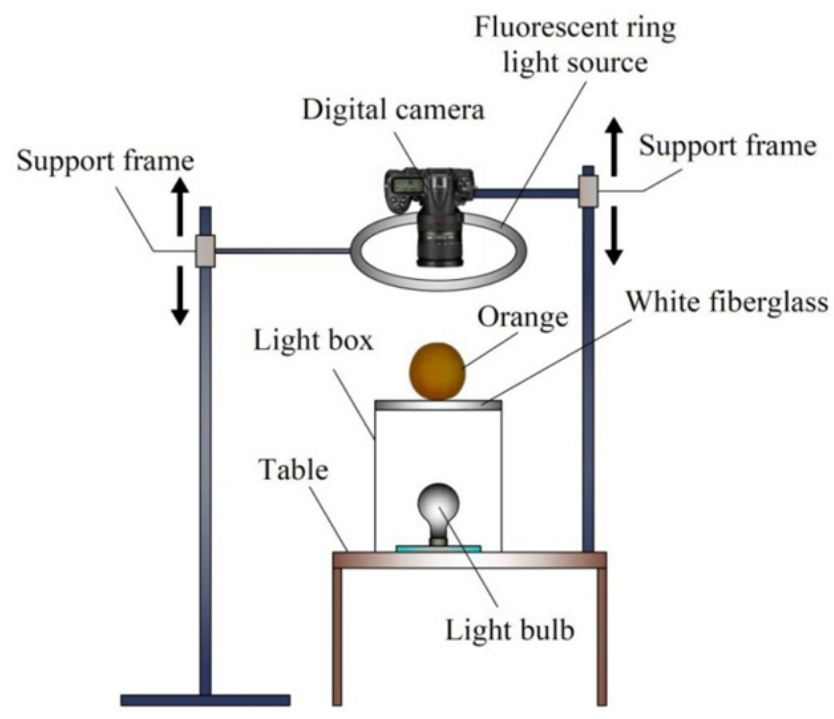

Fig. 1. Image acquisition system

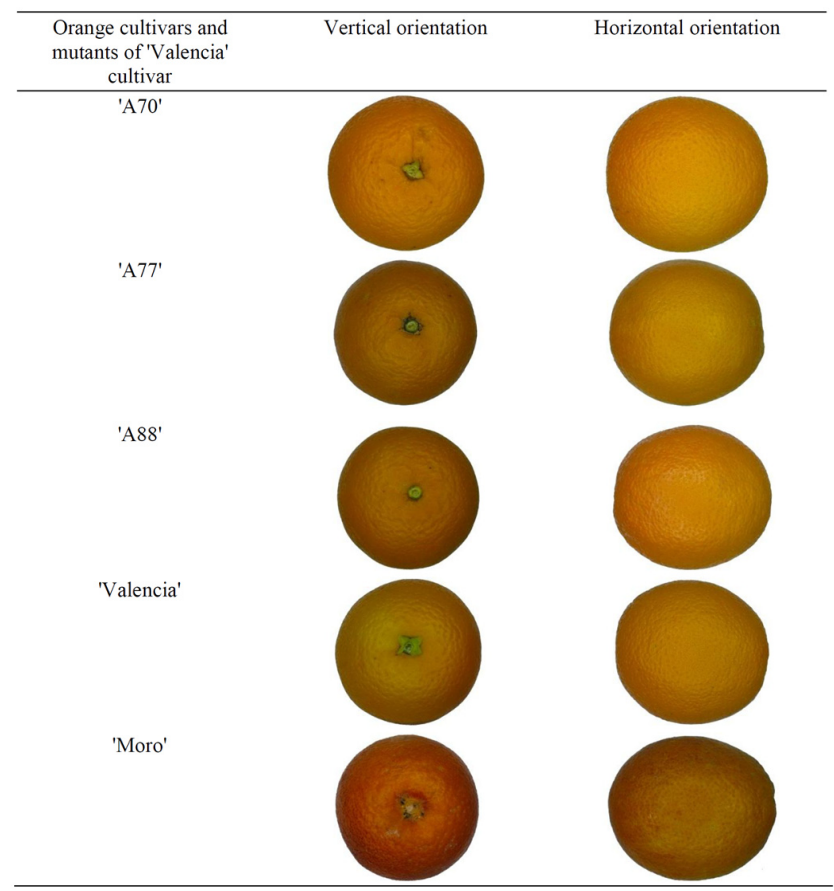

Fig. 2. Orientation of photographs of orange cultivars
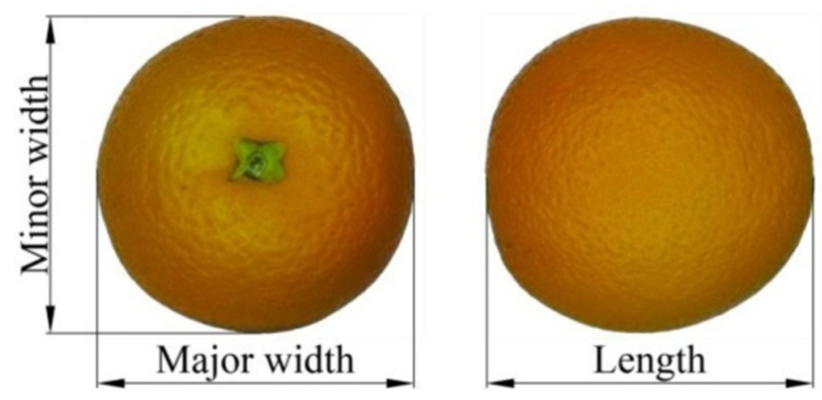

Fig. 3. Length, minor width, and major width of the orange cultivars latitude, $31^{\circ} 32^{\prime} 10^{\prime \prime}$ East longitude, and a 26 meter altitude above sea level) during the 2011 harvest season (December), and were kept in a refrigerator $\left(-4^{\circ} \mathrm{C}\right)$ until subsequent analyses. For each orange cultivar and mutant, 40 fruits were randomly collected from the orange trees. All tests were carried out at the Biological Material Laboratory in the Department of Agricultural Machinery, Ataturk University, Erzurum, Turkey, and were completed in four days.

The mass of each fruit was measured using a digital balance with an accuracy of $\pm 0.01 \mathrm{~g}$, and the volume of each fruit was measured using the liquid displacement method (LDM). Toluene $\left(\mathrm{C}_{7} \mathrm{H}_{8}\right)$ was used rather than water, because water is absorbed by the fruits (Mohsenin, 1986).

The image processing system consisted of a digital camera with USB connection, a fluorescent light source (32 $\mathrm{W})$, and a light bulb $(100 \mathrm{~W})$. A white fiberglass $(25 \times 35$ $\mathrm{cm})$ board was placed on the light box to provide a white background. The digital camera (Panasonic Lumix DMCFZ50) was placed at the center of the fluorescent light source. The fluorescent light source and digital camera were mounted on an adjustable frame (Fig. 1). The distance between the fiberglass surface and the camera was set at $60 \mathrm{~cm}$.

Each orange was placed at the center of the camera's field of view, and two RGB colour images were captured before and after manually rotating the orange $90^{\circ}$ around the lateral axis. An image area of approximately $129 \times 97$ $\mathrm{cm}^{2}$ was captured in each photo. SigmaScan Pro 5.0 software was used to determine the size and shape (at vertical and horizontal orientations) of the orange cultivars (Fig. 2 ). In order to calibrate length in millimeters $(\mathrm{mm})$, a steel ruler with intervals of $0.50 \mathrm{~mm}$ was placed beside each of the orange fruits. From the steel ruler and image processing measurements, a conversion factor of $1 \mathrm{~mm}$ to 25 pixels was determined; this conversion factor was used to convert units of measurement from pixels to millimeters in length.

The software automatically determined the projected area $\left(P A, \mathrm{~cm}^{2}\right)$, equivalent diameter $(E D, \mathrm{~mm})$, perimeter $(P, \mathrm{~mm})$, length $(L, \mathrm{~mm})$, major width $\left(D_{l}, \mathrm{~mm}\right)$, minor width $\left(D_{2}, \mathrm{~mm}\right)$, and shape factor $(S F)$ of the selected objects. The length, major width, and minor width of the fruits are shown in Fig. 3.

The geometric mean diameter $(D, \mathrm{~mm})$ and sphericity $(\varphi, \%)$ were calculated using Equations (1) and (2), respectively (Mohsenin, 1986):

$$
\begin{aligned}
& D_{g}=\left(L \cdot D_{1} \cdot D_{2}\right)^{(1 / 3)} \\
& \varphi=\left(D_{g} / L\right)^{\circ} \times 100
\end{aligned}
$$

The surface area $\left(S, \mathrm{~mm}^{2}\right)$ calculated by Equation (3) was established by McCabe et al. (1986) and cited by Olajide and Ade-Omowaye (1999):

$$
S=\pi \cdot D_{g}^{2}
$$

Fruit density $\left(D, \mathrm{~kg} \mathrm{~m}^{-3}\right)$ was calculated using Equation (4) (Meisami-asl et al., 2009).

$D=$ Fruit mass / Fruit volume 
Shape factor $(S F)$ was calculated using the values of projected area $(P A)$ and perimeter $(P)$ (SigmaScan'Pro, 2004). $S F$ was automatically calculated by SigmaScan software using Equation (5):

$$
S F=4 \cdot \pi \cdot P A / P^{2}
$$

Elongation $(E)$ determined from the vertical and horizontal orientations was calculated separately using Equation (6) (Firatligil-Durmuş et al., 2010):

$E=$ Major axis length/Minor axis length

The size and shape of the five orange cultivars were determined from 40 samples of each cultivar and mutant, totaling 200 samples. SPSS statistical software was used for analysis of variance, and the difference between mean values was compared using Duncan's Multiple Comparison Test (IBM SPSS Statistics, 2010) with a 95\% confidence level $(\mathrm{P}=0.05)$. Mean values $(\bar{X})$ were tabulated with the standard deviation $(\mathrm{SD})$, range (minimum and maximum values), and coefficient of variation $(\mathrm{CV}, \%=[\mathrm{SD} / \bar{X}] \times$ 100). The principle component analysis (PCA) was applied to the pooled data to estimate the variability among the size and shape of the five orange cultivars. The relationships were determined from a covariance matrix derived from the mean size and shape and output data sets consisting of eigenvalues, eigenvectors, and principle component scores.

\section{Results and discussion}

The mean mass $(248.80 \mathrm{~g})$, volume $\left(272.70 \mathrm{~cm}^{3}\right)$, geometric mean diameter $(77.31 \mathrm{~mm})$, and surface area $\left(188.87 \mathrm{~cm}^{2}\right)$ of the 'A70' mutant were significantly greater than those of the other cultivars and mutants. The mean of these features was not statistically different among 'A77', 'A88,' 'Valencia', and 'Moro' (Tab. 1). Cavalcante et al. (2006) determined that the mass of eighteen orange cultivars varied between 168.33 and 237.77 grams. Topuz et al. (2005) found that the mass of several orange cultivars ('Alanya,' 'Finike', 'Washington Navel', and 'Shamouti') ranged from 175.71 to 271.40 grams. The volume of these cultivars varied from 206.68 to $300.44 \mathrm{~cm}^{3}$, the geometric mean diameter ranged from 70.76 to $80.90 \mathrm{~mm}$, and the surface area ranged from 162.2 to $202.6 \mathrm{~cm}^{2}$. A comparison between these results and those obtained in the present study indicate that the findings regarding the physical properties of the orange cultivars and mutants are in concordance with these data. The fruit density values of the 'A77' mutant and the 'Valencia' and 'Moro' cultivars varied from 942.60 to $946.28 \mathrm{~kg} \mathrm{~m}^{-3}$, followed by the 'A88' $\left(930.05 \mathrm{~kg} \mathrm{~m}^{-3}\right)$ and 'A70' mutants $\left(914.99 \mathrm{~kg} \mathrm{~m}^{-3}\right)$.

Sharifi et al. (2007) found that the fruit density of small, medium, and large orange fruits ('Thompson Navel' cultivar) ranged from 999 to $1046 \mathrm{~kg} \mathrm{~m}^{-3}$. In a study by Topuz et al. (2005), fruit densities of the cultivars, 'Alanya', 'Finike, 'Washington Navel', and 'Shamouti', varied from 865.55 to $906.74 \mathrm{~kg} \mathrm{~m}^{-3}$, which was lower than that of the 'Thompson Navel' cultivar. In the present study, fruit density data of the 'A70', 'A77', and 'A88' mutants and 'Valencia' and 'Moro' cultivars were within the limits of the above-mentioned studies with orange cultivars. The highest values of sphericity were obtained from the 'A88' mutant (97.18\%) followed by the 'Valencia' cultivar (96.59\%), the 'A70' (96.41\%) and 'A77' mutants (95.67\%), and the 'Moro' cultivar (95.12\%). The sphericity of the five orange cultivars and mutants used in this study was higher

Tab. 1. Mass, volume, density, geometric mean diameter, sphericity, and surface area of the orange cultivars and mutants (mean \pm standard deviation)

\begin{tabular}{|c|c|c|c|c|c|c|}
\hline \multirow{2}{*}{ Features } & & \multicolumn{5}{|c|}{ Orange cultivars and mutants } \\
\hline & & 'A70' & 'A77' & 'A88' & 'Valencia' & 'Moro' \\
\hline \multirow{3}{*}{$\begin{array}{l}\text { Mass } \\
(\mathrm{g})\end{array}$} & Mean & $248.80 \pm 43.80 \mathrm{a}^{1}$ & $191.27 \pm 23.43 b$ & $199.75 \pm 23.39 b$ & $190.33 \pm 41.04 b$ & $192.54 \pm 39.14 \mathrm{~b}$ \\
\hline & Range & $172.51-349.87$ & $151.37-241.08$ & $151.56-250.65$ & $123.96-293.02$ & $118.53-252.26$ \\
\hline & $\mathrm{CV} \%$ & 17.60 & 12.25 & 11.71 & 21.56 & 20.33 \\
\hline \multirow{3}{*}{$\begin{array}{l}\text { Volume } \\
\left(\mathrm{cm}^{3}\right)\end{array}$} & Mean & $272.70 \pm 52.47 \mathrm{a}$ & $202.58 \pm 26.17 b$ & $215.45 \pm 29.80 b$ & $203.38 \pm 50.02 b$ & $204.30 \pm 44.94 \mathrm{~b}$ \\
\hline & Range & $193-387$ & $164-254$ & $154-290$ & $129-333$ & $123-272$ \\
\hline & $\mathrm{CV} \%$ & 19.24 & 12.92 & 13.83 & 24.59 & 22.00 \\
\hline \multirow{3}{*}{$\begin{array}{l}\text { Density } \\
\left(\mathrm{kg} \mathrm{m}^{-3}\right)\end{array}$} & Mean & $914.99 \pm 21.96 \mathrm{c}$ & $945.20 \pm 23.37 \mathrm{a}$ & $930.05 \pm 29.71 b$ & $942.60 \pm 35.70 \mathrm{ab}$ & $946.28 \pm 32.20 \mathrm{a}$ \\
\hline & Range & $872.82-951.41$ & $887.25-990.85$ & $842.55-1000.95$ & $879.27-1050.9$ & $869.96-1023.06$ \\
\hline & $\mathrm{CV} \%$ & 2.40 & 2.47 & 3.19 & 3.79 & 3.40 \\
\hline \multirow{3}{*}{$\begin{array}{c}\text { Geometric mean } \\
\text { diameter } \\
(\mathrm{mm})\end{array}$} & Mean & $77.31 \pm 5.94 a$ & $67.77 \pm 4.02 b$ & $68.63 \pm 4.09 \mathrm{~b}$ & $67.37 \pm 6.86 \mathrm{~b}$ & $67.51 \pm 6.79 b$ \\
\hline & Range & $67.57-90.00$ & $60.39-76.77$ & $59.43-78.36$ & $55.48-82.12$ & $54.54-78.43$ \\
\hline & CV\% & 7.68 & 5.93 & 5.96 & 10.18 & 10.06 \\
\hline \multirow{3}{*}{$\begin{array}{c}\text { Sphericity } \\
(\%)\end{array}$} & Mean & $96.41 \pm 2.08 \mathrm{ab}$ & $95.67 \pm 1.45 \mathrm{bc}$ & $97.18 \pm 1.39 \mathrm{a}$ & $96.59 \pm 1.93 \mathrm{a}$ & $95.12 \pm 2.47 \mathrm{c}$ \\
\hline & Range & $91.43-99.82$ & $90.94-98.75$ & $94.83-99.55$ & $92.86-99.77$ & $88.38-99.78$ \\
\hline & $\mathrm{CV} \%$ & 2.16 & 1.52 & 1.43 & 2.00 & 2.60 \\
\hline \multirow{3}{*}{$\begin{array}{l}\text { Surface area } \\
\qquad\left(\mathrm{cm}^{2}\right)\end{array}$} & Mean & $188.87 \pm 29.31 \mathrm{a}$ & $144.79 \pm 17.35 b$ & $148.49 \pm 17.66 b$ & $144.04 \pm 29.33 b$ & $144.61 \pm 28.52 b$ \\
\hline & Range & $143.44-254.48$ & $114.57-185.16$ & $110.96-192.92$ & $96.69-211.83$ & $93.44-193.23$ \\
\hline & $\mathrm{CV} \%$ & 15.52 & 11.98 & 11.89 & 20.36 & 19.72 \\
\hline
\end{tabular}

${ }^{1}$ Mean followed by the same letter in the row do not differ from one other as determined by the Duncan's Multiple Range test at a $5 \%$ significance level 
than those of the small, medium, and large grades (92.3\%, 93.1\%, and 94.8\%) of the orange cultivar, 'Thompson', as reported by Sharifi et al. (2007). The CV value of the 'Valencia' cultivar was highest in mass, volume, density, geometric mean diameter, and surface area. The second $\mathrm{CV}$ value was found in the 'Moro' cultivar for all these parameters. The $\mathrm{CV}$ values of the 'A77' and 'A88' mutants were the lowest of the physical properties. The $\mathrm{CV}$ values of sphericity were highest in the 'Moro' cultivar; the 'A70' mutant and 'Valencia' cultivar had similar values.

The high $\mathrm{R}^{2}$ values indicate that the equations shown in Fig. 4, may be adequate for designing and developing a specific sizing system for oranges based on their masses and

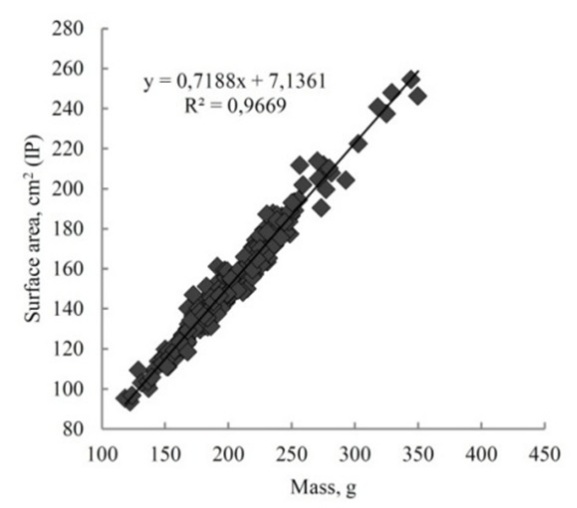

(a)

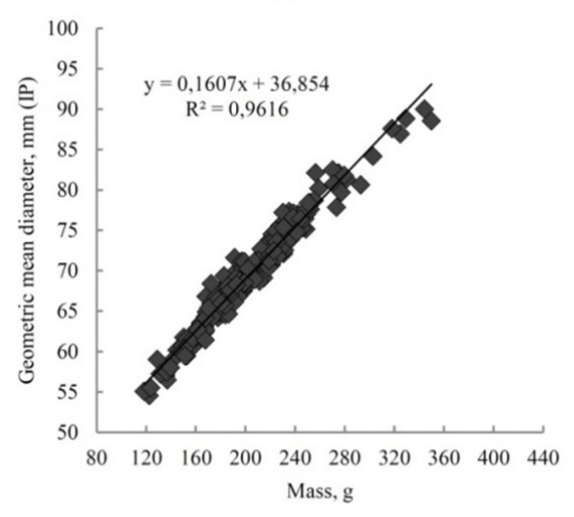

(c) volumes, and for estimating the surface area and geometric mean diameter of the orange cultivars and mutants.

Firatligil-Durmuş et al. (2010) reported a prediction equation for the surface area of the white bean (Phaseolus vulgaris). The $\mathrm{R}^{2}$ value showing the relationship between mass and surface area was 0.7891 for the white bean. Eifert et al. (2006) developed regression equations relating fruit mass to surface area and fruit mass to volume. The authors generated linear equations to predict the surface area of apples, cantaloupe (Cucumis melo), strawberry (Fragaria ananassa), and tomato from mass measurements with $\mathrm{R}^{2}$ equaling $0.47,0.75,0.96$, and 0.87 , respectively. Meisami-asl et al. (2009) developed a multiple linear equation

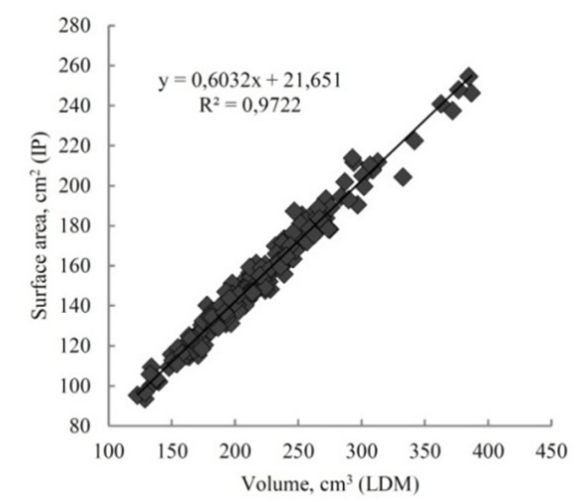

(b)

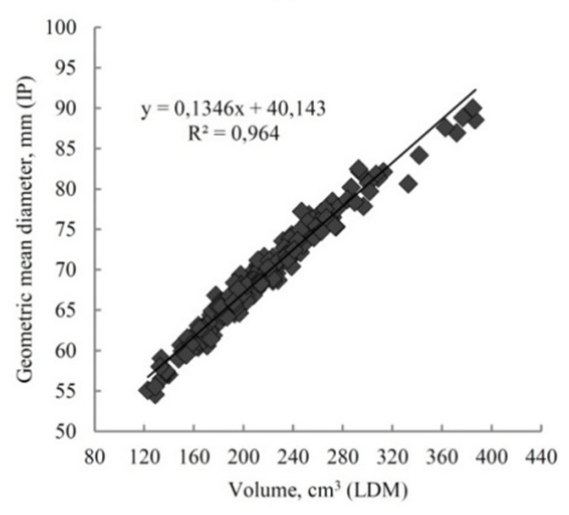

(d)

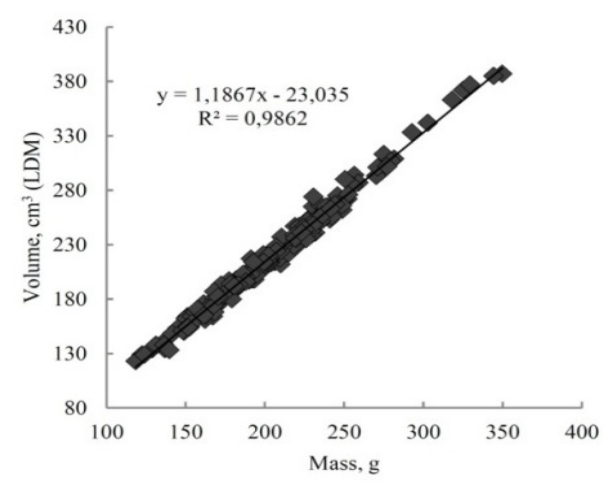

(e)

Fig. 4. The relationship between the physical properties of the orange cultivars and mutants 
238

$\left(\mathrm{R}^{2}=0.999\right)$ to predict the mass of an apple, and found that its mass is dependent upon independent variables of volume and solid density. Bovi and Spiering (2002) determined a linear equation with $\mathrm{R}^{2}$ equal to 0.98 between the peach palm (Bactris gasipaes) fruit surface area, as estimated by digitalization and gravimetric methods. Rashidi et al. (2009) reported that the cantaloupe volume, as determined by the image processing method, was not different from the volume measured by the water displacement method. Clayton et al. (1995) developed non-linear regression models where both fruit mass and volume were used to predict the surface area of apples. Wang and Nguang (2007) designed a way of automatically computing the volume and surface area of axi-symmetric agricul- tural products such as eggs, lemons (Citrus limon), limes (Citrus aurantifolia), and tamarillos (Solanum betaceum).

Ranges of projected surface area, equivalent diameter, perimeter, shape factor, and elongation, obtained from the two orientations (horizontal and vertical) of the five orange cultivars and mutants are shown in Fig. 5. The values of the projected surface area, equivalent diameter, and perimeter were similar for the two orientations. The values of shape obtained from the vertical orientation had narrower ranges than that of the horizontal orientation and skewed to the left. The results of elongation obtained from the vertical orientation showed that the five orange cultivars and mutants had more circularity than the elongation obtained from the horizontal orientation.
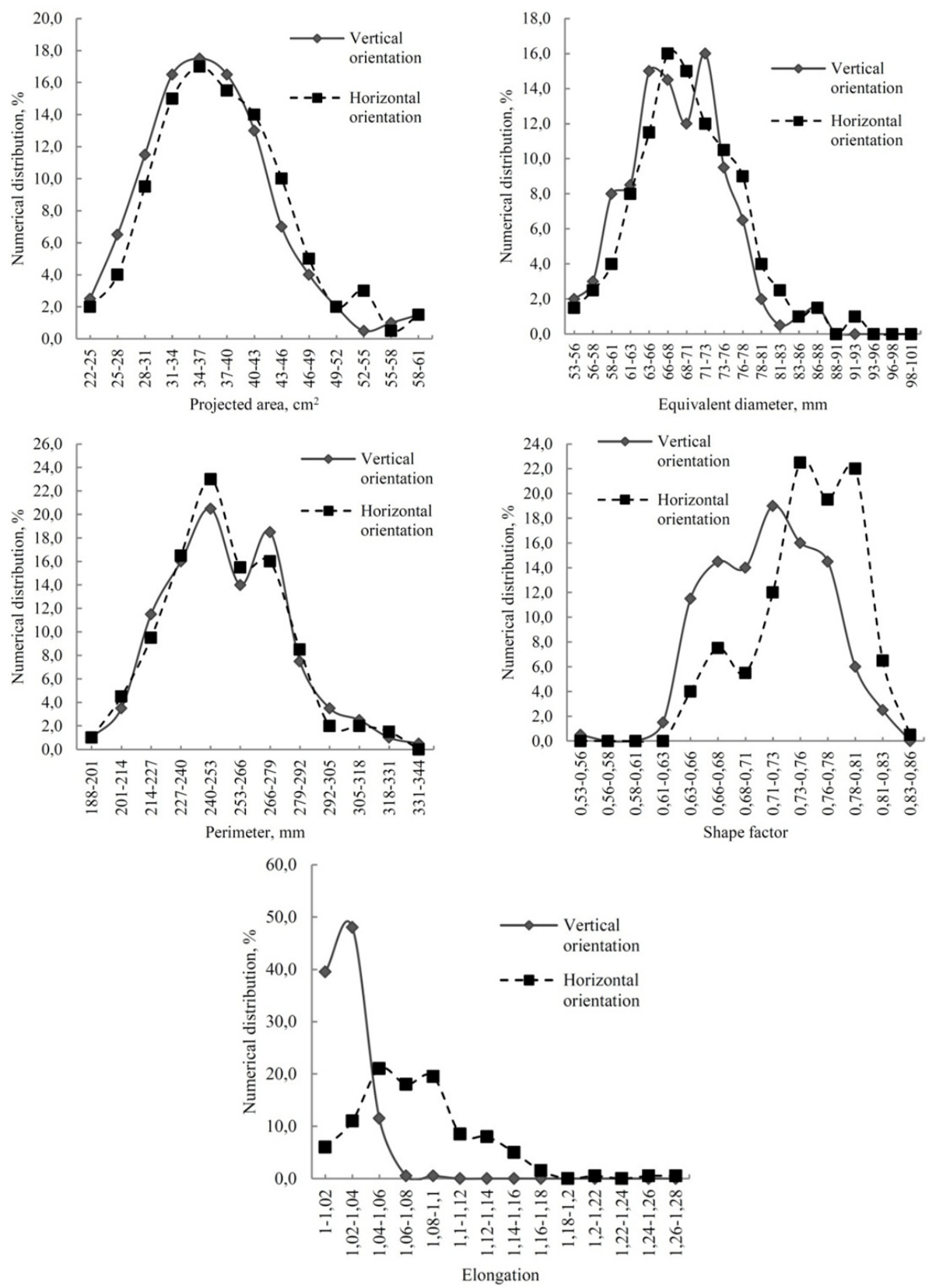

Fig. 5. Numerical distribution of size and shape of the orange cultivars and mutants 
The length in the horizontal orientation and the major and minor width in the vertical orientation of the five orange cultivars and mutants ranged from $69.79-80.29 \mathrm{~mm}$,

66.65-76.91 mm, and 64.98-74.88 mm, respectively (Tab. 2). The length $(80.29 \mathrm{~mm})$, major width $(76.91 \mathrm{~mm})$, and minor width $(74.88 \mathrm{~mm})$ of the 'A70' mutant were the Tab. 2. Length and minor and major width of the orange cultivars and mutants (mean \pm standard deviation)

\begin{tabular}{|c|c|c|c|c|c|c|}
\hline \multirow{2}{*}{ Features } & & \multicolumn{5}{|c|}{ Orange cultivars and mutants } \\
\hline & & 'A70’ & 'A77' & 'A88’ & 'Valencia' & 'Moro' \\
\hline \multirow{3}{*}{$\begin{array}{l}\text { Length } \\
(\mathrm{mm})\end{array}$} & Mean & $80.29 \pm 7.19 \mathrm{a}^{1}$ & $70.88 \pm 4.72 b$ & $70.56 \pm 4.51 b$ & $69.79 \pm 7.85 b$ & $71.09 \pm 8.22 \mathrm{~b}$ \\
\hline & Range & $68.27-96.31$ & $61.62-83.14$ & $62.13-80.67$ & $56.89-86.59$ & $54.75-82.79$ \\
\hline & $\mathrm{CV} \%$ & 8.96 & 6.66 & 6.39 & 11.25 & 11.56 \\
\hline \multirow{3}{*}{$\begin{array}{l}\text { Major width } \\
\quad(\mathrm{mm})\end{array}$} & Mean & $76.91 \pm 5.55 a$ & $66.98 \pm 3.84 \mathrm{~b}$ & $68.49 \pm 3.98 b$ & $66.98 \pm 6.59 b$ & $66.65 \pm 6.34 \mathrm{~b}$ \\
\hline & Range & $68.05-88.87$ & $60.26-74.97$ & $59.26-77.61$ & $55.45-81.3$ & $54.33-77.95$ \\
\hline & CV\% & 7.22 & 5.73 & 5.81 & 9.84 & 9.51 \\
\hline \multirow{3}{*}{$\begin{array}{l}\text { Minor width } \\
\quad(\mathrm{mm})\end{array}$} & Mean & $74.88 \pm 5.46 a$ & $65.58 \pm 3.73 b$ & $66.91 \pm 4.03 b$ & $65.44 \pm 6.42 b$ & $64.98 \pm 6.2 b$ \\
\hline & Range & $65.77-86.22$ & $59.32-72.93$ & $57.01-76.86$ & $54.13-79.68$ & $52.53-76.37$ \\
\hline & $\mathrm{CV} \%$ & 7.29 & 5.69 & 6.02 & 9.81 & 9.54 \\
\hline
\end{tabular}

${ }^{1}$ Mean followed by the same letter in the row do not differ from one other as determined by the Duncan's Multiple Range test at a $5 \%$ significance level

Tab. 3. Projected area, equivalent diameter, perimeter, shape factor, and elongation of the orange cultivars and mutants (mean \pm standard deviation)

\begin{tabular}{|c|c|c|c|c|c|c|}
\hline \multirow{2}{*}{ Features } & & \multicolumn{5}{|c|}{ Orange cultivars and mutants in the vertical orientation } \\
\hline & & 'A70' & 'A77' & 'A88' & 'Valencia' & 'Moro' \\
\hline \multirow{3}{*}{$\begin{array}{l}\text { Projected area } \\
\qquad\left(\mathrm{cm}^{2}\right)\end{array}$} & Mean & $45.04 \pm 6.50 \mathrm{a}^{1}$ & $34.34 \pm 3.89 \mathrm{~b}$ & $35.85 \pm " b$ & $34.46 \pm ” b$ & $33.97 \pm 6.39 b$ \\
\hline & Range & $34.83-59.24$ & $27.84-42.71$ & $26.61-46.33$ & $23.39-50.34$ & $22.23-46.29$ \\
\hline & $\mathrm{CV} \%$ & 14.43 & 11.33 & 11.74 & 19.38 & 18.81 \\
\hline \multirow{3}{*}{$\begin{array}{l}\text { Equivalent diameter } \\
\qquad(\mathrm{mm})\end{array}$} & Mean & $75.54 \pm 5.39 \mathrm{a}$ & $66.02 \pm 3.71 b$ & $67.45 \pm 3.96 b$ & $65.93 \pm 6.40 \mathrm{~b}$ & $65.47 \pm 6.25 b$ \\
\hline & Range & $66.59-86.85$ & $59.54-73.74$ & $58.21-76.81$ & $54.57-80.06$ & $53.21-76.77$ \\
\hline & $\mathrm{CV} \%$ & 7.14 & 5.62 & 5.87 & 9.71 & 9.55 \\
\hline \multirow{3}{*}{$\begin{array}{l}\text { Perimeter } \\
\quad(\mathrm{mm})\end{array}$} & Mean & $281.96 \pm 23.13 \mathrm{a}$ & $246.72 \pm 16.56 b$ & $251.02 \pm 18.56 b$ & $244.98 \pm 24.26 b$ & $243.7327 .14 \pm b$ \\
\hline & Range & $240.33-333.45$ & 219.1-276.94 & $217.73-305.55$ & $195.82-301.38$ & $195.39-299.65$ \\
\hline & $\mathrm{CV} \%$ & 8.20 & 6.71 & 7.39 & 9.90 & 11.14 \\
\hline \multirow{3}{*}{ Shape factor } & Mean & $0.71 \pm 0.05 a$ & $0.71 \pm 0.05 \mathrm{a}$ & $0.72 \pm 0.05 a$ & $0.72 \pm 0.05 a$ & $0.72 \pm 0.05 a$ \\
\hline & Range & $0.63-0.81$ & $0.63-0.81$ & $0.54-0.82$ & $0.63-0.81$ & $0.63-0.81$ \\
\hline & $\mathrm{CV} \%$ & 7.04 & 7.04 & 6.94 & 6.94 & 6.94 \\
\hline \multirow{5}{*}{ Elongation } & Mean & $1.03 \pm 0.02 \mathrm{a}$ & $1.02 \pm 0.01 \mathrm{a}$ & $1.02 \pm 0.01 \mathrm{a}$ & $1.02 \pm 0.02 \mathrm{a}$ & $1.03 \pm 0.01 \mathrm{a}$ \\
\hline & Range & $1.00-1.06$ & $1.00-1.04$ & $1.01-1.05$ & $1.00-1.08$ & $1.00-1.06$ \\
\hline & $\mathrm{CV} \%$ & 1.46 & 0.78 & 1.17 & 1.46 & 1.17 \\
\hline & & \multicolumn{5}{|c|}{ Orange cultivars and mutants in the horizontal orientation } \\
\hline & & 'A70' & 'A77' & 'A88' & 'Valencia' & 'Moro' \\
\hline \multirow{3}{*}{$\begin{array}{l}\text { Projected area } \\
\qquad\left(\mathrm{cm}^{2}\right)\end{array}$} & Mean & $46.77 \pm 8.01 \mathrm{a}$ & $36.35 \pm 4.36 \mathrm{~b}$ & $36.48 \pm 4.31 \mathrm{~b}$ & $35.68 \pm 7.52 b$ & $36.15 \pm 7.26 b$ \\
\hline & Range & $35.54-64.87$ & $28.04-46.97$ & $28.51-47.94$ & $23.42-54.50$ & $22.45-48.10$ \\
\hline & CV\% & 17.13 & 11.99 & 11.81 & 21.08 & 20.08 \\
\hline \multirow{3}{*}{$\begin{array}{l}\text { Equivalent diameter } \\
\qquad(\mathrm{mm})\end{array}$} & Mean & $76.90 \pm 6.53 \mathrm{a}$ & $67.91 \pm 4.04 \mathrm{~b}$ & $68.04 \pm 4.01 \mathrm{~b}$ & $67.05 \pm 7.03 \mathrm{~b}$ & $67.50 \pm 6.92 b$ \\
\hline & Range & $67.27-90.88$ & $59.75-77.33$ & $60.25-78.13$ & $54.60-83.30$ & $53.46-78.26$ \\
\hline & $\mathrm{CV} \%$ & 8.49 & 5.95 & 5.89 & 10.48 & 10.25 \\
\hline \multirow{3}{*}{$\begin{array}{l}\text { Perimeter } \\
\quad(\mathrm{mm})\end{array}$} & Mean & $277.76 \pm 23.15 a$ & $247.97 \pm 15.39 b$ & $246.31 \pm 15.13 b$ & $246.51 \pm 25.36 b$ & $244.49 \pm 28.76 b$ \\
\hline & Range & $235.99-322.36$ & $223.8-290.65$ & $218.32-282.45$ & $203.4-318.25$ & $188.64-291.95$ \\
\hline & $\mathrm{CV} \%$ & 8.33 & 6.21 & 6.14 & 10.29 & 11.76 \\
\hline \multirow{3}{*}{ Shape factor } & Mean & $0.76 \pm 0.04 a$ & $0.74 \pm 0.05 \mathrm{ab}$ & $0.75 \pm 0.03 a$ & $0.73 \pm 0.05 b$ & $0.760 .05 \pm \mathrm{a}$ \\
\hline & Range & $0.66-0.81$ & $0.65-0.83$ & $0.67-0.81$ & $0.64-0.81$ & $0.65-0.82$ \\
\hline & CV\% & 5.26 & 6.76 & 4.00 & 6.85 & 6.58 \\
\hline \multirow{3}{*}{ Elongation } & Mean & $1.08 \pm 0.04 a b$ & $1.08 \pm 0.04 \mathrm{ab}$ & $1.07 \pm 0.03 \mathrm{~b}$ & $1.07 \pm 0.04 \mathrm{~b}$ & $1.10 \pm 0.06 \mathrm{a}$ \\
\hline & Range & $1.01-1.15$ & $1.01-1.21$ & $1.01-1.13$ & $1.01-1.15$ & $1.02-1.27$ \\
\hline & CV\% & 3.53 & 3.52 & 2.54 & 3.55 & 5.57 \\
\hline
\end{tabular}

${ }^{1}$ Mean followed by the same letter in the row do not differ from one other as determined by the Duncan's Multiple Range test at a $5 \%$ significance level 
240

highest of the other cultivars. The obtained data for the length of 'A77', 'A88', 'Valencia', and 'Moro' varied from 69.79 to $71.09 \mathrm{~mm}$, which was similar to the data for the 'Alanya' (69.21 mm) and 'Finike' cultivars $(69.44 \mathrm{~mm})$, as reported by Topuz et al. (2005). Cavalcante et al. (2006) reported that the length and width of seventeen orange cultivars ranged from 68.6 to $75.7 \mathrm{~mm}$ and 68.3 to 73.0 $\mathrm{mm}$, respectively.

The projected surface area, equivalent diameter, perimeter, shape factor, and elongation in the vertical and horizontal orientations of the five orange cultivars and mutants are shown in Tab. 3.

The data obtained from the 'A70' mutant was highest for projected surface area, equivalent diameter, and perimeter, with a mean of $45.04 \mathrm{~cm}^{2}, 75.54 \mathrm{~mm}$, and 281.96 $\mathrm{mm}$, respectively in the vertical orientation, and 46.77 $\mathrm{cm}^{2}, 76.90 \mathrm{~mm}$, and $277.76 \mathrm{~mm}$, respectively in the horizontal orientation. The projected surface area, equivalent diameter, and perimeter of the 'A77', and 'A88' mutants, and the 'Valencia' and 'Moro' cultivars ranged from 33.97 to $35.85 \mathrm{~cm}^{2}, 65.47$ to $67.45 \mathrm{~mm}$, and 243.73 to 251.02 $\mathrm{mm}$, respectively in the vertical orientation, and 35.68 to $36.48 \mathrm{~cm}^{2}, 67.05$ to $68.04 \mathrm{~mm}$, and 244.49 to 247.97 $\mathrm{mm}$, respectively in the horizontal orientation. The mean of these parameters was not statistically different for 'A77', 'A88, 'Valencia', and 'Moro'. According to data obtained by Topuz et al. (2005), the ratio of the projected surface area of the four orange cultivars, determined from the horizontal orientation and vertical orientation, was in the range of 1.031 to 1.098 . This ratio was found in the range of 1.018 to 1.064 for the five orange cultivars used in this study. The value of the 'A70' mutant, which had the highest projected area in this study, was a little smaller than the 'Alanya' $\left(49.14 \mathrm{~cm}^{2}\right)$ and 'Finike' cultivars $\left(49.11 \mathrm{~cm}^{2}\right)$, as reported by Topuz et al. (2005).

In the vertical orientation, the orange cultivars and mutants showed statistical similarity in shape and elongation, the values of which ranged from 0.71 to 0.72 and from 1.02 and 1.03 , respectively. However, the parameters obtained from the horizontal orientation were found to be statistically different. The lowest shape factor (0.73) was found in the 'Valencia' cultivar. The elongation of 'A88' and 'Valencia', which had a mean of 1.07 , were smaller than those of the other cultivars, which varied from 1.08 to 1.10 . These data were compatible with the data from Sharifi et al. (2007). In their study, the ratio of length:width of small, medium, and large orange grades of the 'Thompson Navel' cultivar, which is also considered elongation, ranged from 1.063 to 1.104 .

The highest $\mathrm{CV}$ for the projected surface area, equivalent diameter, perimeter, length, major width, and minor width was found in the 'Valencia' and 'Moro' cultivars.

Principle component analysis (PCA) was applied to mean values of measured properties for detecting the most important factors of variability, and to explain the relationship between variables and observations. Tab. 4 , which shows the proportion and cumulative variance of the observed variables, is explained by each of the principle components (PCs). The first three components produced by PCA were found to be $78 \%$ by PC1, $12 \%$ by PC2, and $7 \%$ by $\mathrm{PC} 3$ of the variation, for a total of $97 \%$.

Tab. 4. Coefficients and eigenvalues for the first three principle components (PC) of PCA for the orange cultivars

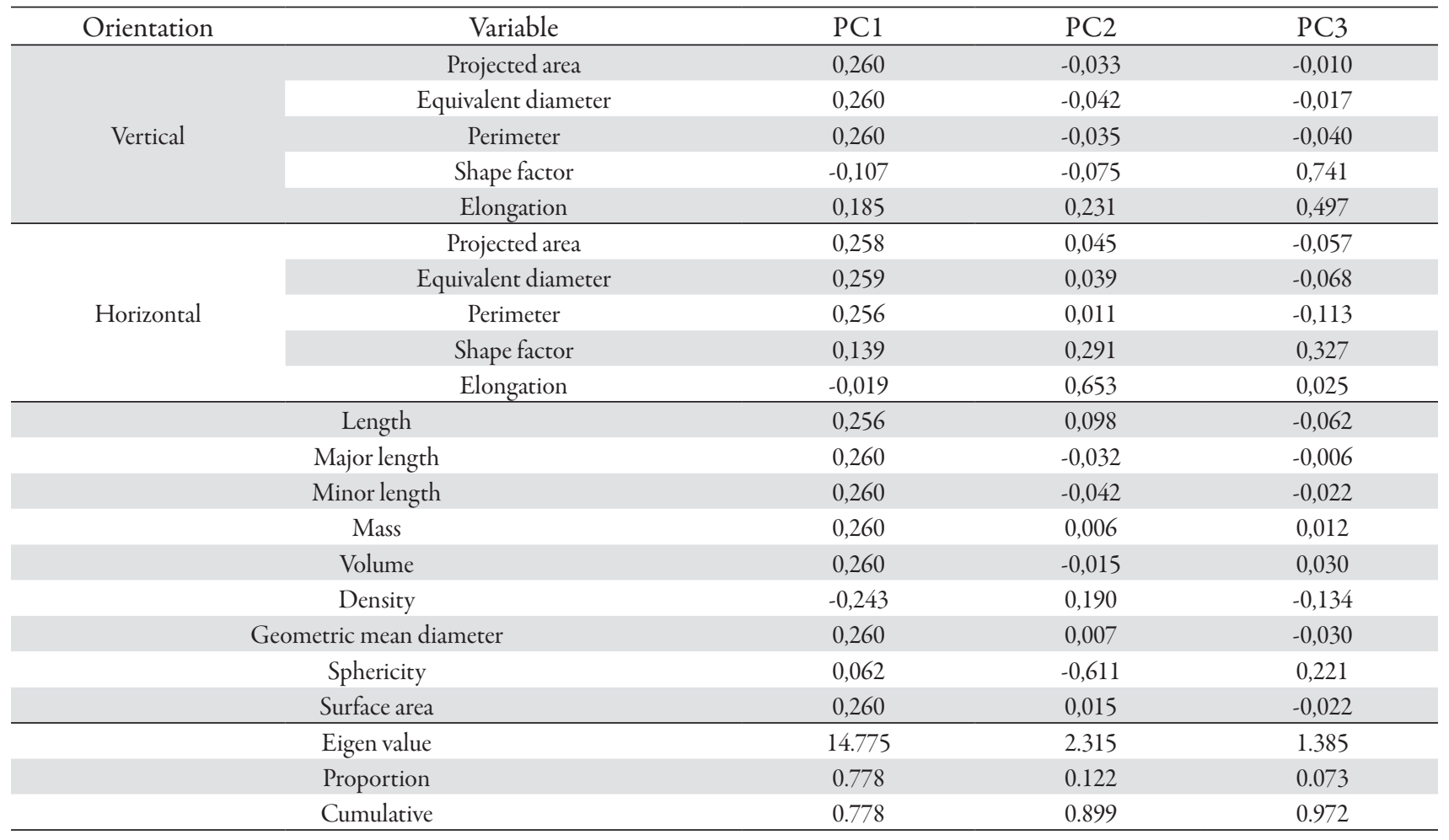




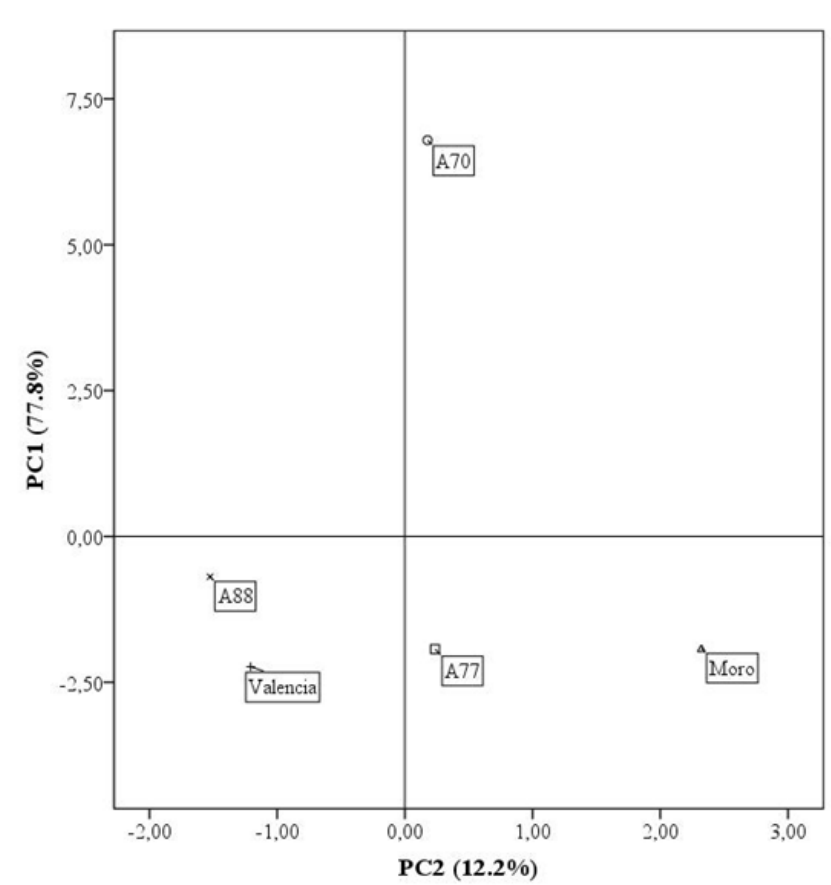

Fig. 6. PCA plot of the first two principle components demonstrating the relationships between the five orange cultivars

The most important variables integrated by the first component (PC1) were projected area, equivalent diameter, and perimeter obtained from the two orientations (vertical and horizontal), length, mass, volume, density, geometric mean diameter, and surface area of the orange cultivars and mutants. The results show that these variables are very important for distinguishing the orange cultivars in terms of dimensional and gravimetric features. PC1 negatively correlated with density, while there was a positive correlation between PC1 and dimensional and other gravimetric features of the orange cultivars. Sphericity negatively correlated with the second component (PC2), while elongation obtained from the horizontal orientation positively correlated with it. The output shows that these descriptors are the second most important variables depicting the roundness features of the orange cultivars. Shape factor obtained from the two orientations and elongation obtained from the vertical orientation of the orange cultivars were the most important variables of the third components (PC3), and these variables incorporated the shape features of the orange cultivars.

PCA produced two components accounting for a cumulative $90 \%$ of variability: The components consisted of dimensional, gravimetric, and roundness features of the orange cultivars. The orange cultivars were plotted on two dimensions based on the PCA results (Fig. 6).

'A70' was placed on the top half of the PC1 axis because of its dimensional and gravimetric features, which were the highest of the cultivars and mutants. Elongation of the 'Moro' cultivar positively correlated with the PC2 axis in the horizontal orientation, and was higher than that of 'A70' and 'A77', their sphericity of which was lower than the 'Moro' cultivar. The plot showed that 'A88' and 'Valencia' had the highest values for sphericity, and the lowest values for elongation in the horizontal orientation. In the present study, PCA was used to explain the variability among the orange cultivars and mutants. PCA outputs supported the results of ANOVA.

\section{Conclusions}

The results of this study show that the projected surface area, equivalent diameter, and perimeter obtained from two orientations (vertical and horizontal), length, mass, volume, density, geometric mean diameter, and surface area are very important in distinguishing the orange cultivars and mutants in terms of dimensional and gravimetric properties. Data from the 'A70' mutant of the 'Valencia' cultivar showed dimensional and gravimetric properties that were higher than those of 'A77', 'A88,' 'Valencia' and 'Moro'. In regard to the roundness properties, the sweet orange cultivar ('Valencia') and its mutants ('A70', 'A77', and 'A88') had the highest values for sphericity, and the lowest elongation values compared to the blood orange cultivar ('Moro').

This study showed that the size and shape of the five orange cultivars and mutants can be used to distinguish them from one to another. These properties can also be used to determine the parameters for sorting and postharvest processing that should be incorporated in the equipment design.

\section{References}

Albertini MV, Carcouet E, Pailly O, Gambotti C, Luro F, Berti L (2006). Changes in organic acids and sugars during early stages of development of acidic and acidless citrus fruit. J Agric Food Chem 54:8335-8339.

Bovi MLA, Spiering SH (2002). Estimating peach palm fruit surface area using allometric relationships. Sci Agric 59(4):717-721.

Cavalcante IHL, Martins, PRG, Stuchi ES (2006). Fruit characteristics of eighteen orange cultivars. Revista de Biologia e Ciencias da Terra 6(2):72-77.

Clayton M, Amos ND, Banks NH, Morton RH (1995). Estimation of apple fruit surface area. New Zeal J Crop Hort 23:345-349.

Eifert JD, Sanglay GC, Lee DJ, (2006). Prediction of raw produce surface area from weight measurement. J Food Eng 74:552-556.

Ercisli S, Kara M, Ozturk I, Sayinci B, Kalkan F (2011). Comparison of some physico-mechanical properties of two walnut (Juglans regia L.) cultivars. Not Bot Horti Agrobo 39(2):227-231.

Ercisli S, Sayinci B, Kara M, Yildiz C, Ozturk I (2012). Determination of size and shape features of walnut (Juglans regia L.) cultivars using image processing. Sci Hortic- 
242

Amsterdam 133:47-55.

FAOSTAT (2009). http://faostat.fao.org/site/567/default. aspx\#ancor - Production. Crops (accessed 31 May 2011).

Firatligil-Durmuş E, Šárka E, Bubník Z (2008). Image vision technology for the characterization of shape and geometrical properties of two varieties of lentil grown in Turkey. Czech J Food Sci 26:109-116.

Fıratlıgil-Durmuş E, Šárka E, Bubník Z, Schejbal M, Kadlec P, (2010). Size properties of legume seeds of different varieties using image analysis. J Food Eng 99:445-451.

IBM SPSS Statistics (2010). SSS Inc. IBM Company Version 19.

Jahromi MK, Jafari A, Rafiee S, Mirasheh R, Mohtasebi SS (2008). Mass modeling of date fruit (cv. 'Zahedi') with some physical characteristics. Am-Eur J Agric Environ Sci $3(1): 127-131$.

Khojastehnazhand M, Omid M, Tabatabaeefar A (2010). Determination of tangerine volume using image processing methods. Int J Food Prop 13:760-770.

McCabe WL, Smith JC, Harriot P (1986). Unit Operations of Chemical Engineering. McGraw-Hill Book Company, New York.

Meisami-asl E, Rafiee S, Keyhani A, Tabatabaeefar A (2009). Some physical properties of apple cv. 'Golab'. Agricultural Engineering International: The CIGRE-journal. Manuscript 1124, XI.March.

Mohsenin NN (1986). Physical properties of plant and animal materials. New York, Gordon and Breach Science Publisher.

Moufida S, Marzouk B (2003). Biochemical characterization of blood orange, sweet orange, lemon, bergamot and bitter orange. Phytochem 62(8):1283-1289.
Niu LY, Wu JH, Liao XJ, Chen F, Wang ZF, Zhao GH, Hu XS (2008). Physicochemical characteristics of orange juice samples from seven cultivars. Agric Sci in China 7:41-47.

Olajide JO, Ade-Omowaye BIO (1999). Some physical properties of locust bean seed. J Agr Eng Res 74:213-215.

Omid M, Khojastehnazhandb M, Tabatabaeefara A (2010). Estimating volume and mass of citrus fruits by image processing technique. J Food Eng 100(2):315-321.

Rashidi M, Gholami M, Abbassi S (2009). Cantaloupe volume determination through image Processing. J Agric Sci Tech 11:623-631.

Sharifi M, Rafiee S, Keyhani A, Jafari A, Mobli H, Rajabipour A, Akram A (2007). Some physical properties of orange (var. Tompson). Int Agrophysics 21:391-397.

SigmaScan Pro (2004). SigmaScan Pro 5.0 User’s Manual. Systat Software, Inc., Point Richmond, CA 94804.

Soltani M, Alimardani R, Omid M (2011). Modeling the main physical properties of banana fruit based on geometrical attributes. Int J Multidiscip Sci Eng 2(2):1-6.

Tabatabaeefar, A, Rajabipour A (2005). Modeling the mass of apples by geometrical attributes. Sci Hortic-Amsterdam 105:373-382.

Taheri-Garavand A, Rafiee S, Keyhani A (2011). Study on some morphological and physical characteristics of tomato used in mass models to characterize best post harvesting options. Aus. J Crop Sci 5(4):433-438.

Topuz A, Topakci M, Canakci M, Akinci I, Ozdemir F (2005). Physical and nutritional properties of four orange varieties. J Food Eng 66:519-523.

Wang TY, Nguang SK (2007). Low cost sensor for volume and surface area computation of axi-symmetric agricultural products. J Food Eng 79:870-877. 